\section{(1) \\ CrossMark}

\title{
Chronic thromboembolic pulmonary hypertension: the evolving treatment landscape
}

\author{
Nick H. Kim ${ }^{1}$ and Eckhard Mayer ${ }^{2}$ \\ Affiliations: ${ }^{1}$ Division of Pulmonary and Critical Care Medicine, University of California, San Diego, La Jolla, \\ CA, USA. ${ }^{2}$ Kerckhoff Heart and Lung Center, Bad Nauheim, Germany. \\ Correspondence: Nick H. Kim, UC San Diego, Division of Pulmonary and Critical Care Medicine, 9300 \\ Campus Point Drive, MC 7381, La Jolla, CA 92037, USA. E-mail: h33kimaucsd.edu
}

@ERSpublications

PEA is the treatment of choice for operable CTEPH. Riociguat is the first medical therapy for inoperable CTEPH http://ow.ly/LXTZ0

\section{The historical perspective}

Chronic thromboembolic pulmonary hypertension (CTEPH) is a unique form of pulmonary hypertension $(\mathrm{PH})$ arising from the obstruction of pulmonary arterial vessels by organised thromboembolic material [1]. Much like other forms of $\mathrm{PH}, \mathrm{CTEPH}$ has historically proven to be a challenging clinical entity in that it is frequently underdiagnosed and undertreated [1-3]. This lack of clinical recognition can result in patients with CTEPH experiencing progressive $\mathrm{PH}$ and eventual right ventricular failure [1,4]. However, in contrast to other types of $\mathrm{PH}, \mathrm{CTEPH}$ is potentially curable via surgical intervention in the form of pulmonary endarterectomy (PEA) [5], a technique that has roots dating back over half a century [6-8].

One of the earliest descriptions of CTEPH was reported by CARroll [9] in 1950. At this time, the diagnosis of CTEPH was primarily made at autopsy. In 1958, HuRwitT et al. [7] described a surgical technique to remove chronic thrombi from the pulmonary arteries utilising hypothermia and venous inflow occlusion; although the index patient did not survive the operation, the technique was deemed promising. The first successful pulmonary thromboendarterectomy (subsequently also referred to as PEA) for CTEPH was reported by Houk et al. [10] in 1963. This group, 2 years later, reported on a total of four operated cases [11]. Following this landmark series, other groups eventually reported successful results from PEA $[12,13]$. However, the majority of the early pioneering research in CTEPH was carried out at the University of California, San Diego. In 1992, Moser et al. [14] observed "At the outset, (CTEPH) was considered to be a rare autopsy curiosity. However, it has become apparent that CTEPH is not only more common than had been appreciated, but is also potentially subject to surgical cure". In the same paper, they documented their operative mortality rate for patients with CTEPH undergoing PEA as being 12\%; in contrast, a 1984 review of world literature by CHITwoon et al. [8] reported that the same procedure, performed in a total of 85 patients with CTEPH between 1960 and 1983, carried an overall mortality rate of $22 \%$ [14]. This improvement was due to a combination of improved patient diagnosis and operative selection, through better imaging modalities and improved understanding of CTEPH, as well as advances in the PEA surgical technique [14-16].

Interest in CTEPH also grew in parallel with emerging focus and efforts in $\mathrm{PH}$. In the early 1970s, $\mathrm{PH}$ received significant international attention when widespread prescription of the weight-loss stimulant

Received: Feb 122015 | Accepted after revision: Feb 202015

Conflict of interest: Disclosures can be found alongside the online version of this article at err.ersjournals.com

Provenance: Publication of this peer-reviewed article was sponsored by Bayer Pharma AG, Berlin, Germany (principal sponsor, European Respiratory Review issue 136).

Copyright OERS 2015. ERR articles are open access and distributed under the terms of the Creative Commons Attribution Non-Commercial Licence 4.0. 
aminorex in Europe resulted in an epidemic of drug-induced PH [17]. This incident led to the first World Health Organization (WHO) Symposium on Pulmonary Hypertension in 1973 [18]. This was followed in the US, in 1981, by the first registry of primary pulmonary hypertension (PPH), which was sponsored by the National Institutes of Health. Analysis of data from this US registry demonstrated very poor survival for patients diagnosed with PPH (later renamed idiopathic pulmonary arterial hypertension), with 1-, 3 - and 5-year survival rates of $68 \%, 48 \%$ and $34 \%$, respectively [19]. This provided a key stimulus to develop effective treatment options for patients suffering from pulmonary arterial hypertension (PAH). Accordingly, in a relatively short period of time, we went from having none to over a dozen therapeutic options for PAH [19]. With this growth in PAH awareness, we also witnessed growing interest in other forms of $\mathrm{PH}$, which included CTEPH. However, the treatment for CTEPH stayed essentially the same through the growth phase of PAH, and remained surgical with potentially curative PEA [20, 21].

As awareness of $\mathrm{PH}$ and CTEPH grew, it became apparent that many CTEPH patients could not receive PEA for numerous reasons; representing an unmet and growing need in the field of CTEPH. Even in regions with access to a PEA centre, nearly $40 \%$ of CTEPH patients were deemed inoperable for PEA [22]. Reasons for inoperability varied; they included: chronic thromboembolic disease of distal pulmonary arteries beyond the potential reach of PEA; the presence of significant coexisting conditions; and patient refusal to undergo surgery [22]. In addition, $10-35 \%$ of patients who have undergone PEA experience either persistent or recurrent $\mathrm{PH}$ following surgery $[23,24]$. Until recently, none of the PAH-targeted therapies were approved for the treatment of CTEPH [5]. Lung transplantation remained the only potential treatment option available to those patients with CTEPH who were either deemed inoperable or not adequately treated with PEA. However, in reality the role of lung transplantation with its set of challenges, including limited donor availability, made it of limited utility in the treatment of CTEPH [20, 25].

\section{Recent developments}

As a result of the increasing recognition of patients with CTEPH who are either inoperable or who have recurrent/persistent $\mathrm{PH}$ after PEA, clinicians have begun to examine alternative therapeutic options for managing such patients [22]. Some of these are still in the investigative stage, so further evidence is needed to establish the role that each may play in individualised treatment strategies. The overlap between CTEPH and $\mathrm{PAH}$, both in terms of pathophysiology and clinical presentation, provided a sound rationale for investigations into the efficacy of newly developed drugs targeted at patients with PAH as medical therapies for patients with CTEPH [26, 27]. Successive WHO Symposia on Pulmonary Hypertension in 1998, 2003 and 2008 not only led to the adoption and subsequent revision of new classifications for different conditions characterised by $\mathrm{PH}$, which included $\mathrm{CTEPH}$ in its own category, but also highlighted the need for PAH-targeted therapies [28-30]. This unmet need, together with an improved understanding of the pathophysiology of $\mathrm{PAH}$, e.g. the roles of the endothelin and prostacyclin pathways [31, 32], led to the development of various targeted and effective pharmacotherapies for $\mathrm{PAH}$. This has resulted in a growing off-label use of $\mathrm{PAH}$ medications, such as endothelin receptor antagonists, phosphodiesterase type 5 inhibitors and prostacyclin analogues, in patients with CTEPH deemed unsuitable for surgery or with persistent/recurrent PH after PEA. However, there has been limited evidence, to date, that any of these $\mathrm{PAH}$-specific therapies have a significant effect on clinically relevant end-points for patients with CTEPH $[33,34]$.

Given that PEA offers little to no benefit for patients deemed inoperable and those with persistent/ recurrent $\mathrm{PH}$ following surgery, the recent approval of the novel agent riociguat as the first and only medical therapy for CTEPH represents a major advance in the management of this condition [5]. Riociguat is a soluble guanylate cyclase (sGC) stimulator that restores the nitric oxide-sGC-cyclic guanosine monophosphate pathway, which is impaired in the pathogenesis of $\mathrm{PH}$ [35]. In the CHEST-1 study (Chronic Thromboembolic Pulmonary Hypertension Soluble Guanylate Cyclase-Stimulator Trial 1), riociguat demonstrated significant efficacy across a range of clinically meaningful end-points, including exercise capacity, functional class and haemodynamics, in patients with inoperable CTEPH and those with persistent/recurrent PH following PEA [36]. Further to this, riociguat has been shown to have a favourable safety profile and initial long-term follow-up data suggest that the benefits derived from treatment with riociguat are sustained for up to 1 year [37].

Pharmacological agents may have a role as bridging therapy prior to PEA, particularly in patients with high preoperative pulmonary vascular resistance levels and distal disease. However, to date only limited studies have tested pharmacological therapies in this preoperative setting with mixed postoperative outcomes [38-42]. Further studies, including those with new drugs such as riociguat, are needed to determine the value and safety of this strategy. Accordingly, all operable cases should proceed to PEA, without delay, or trial of medical therapy. 
A catheter-based intervention showing promise for inoperable CTEPH patients is balloon pulmonary angioplasty (BPA), a percutaneous technique that was initially reported by Voorburg et al. [43] in 1988. Subsequent reports in the treatment of inoperable CTEPH demonstrated benefit in a few select cases, but highlighted the dangers of BPA with numerous serious complications including death [44, 45]. More recent studies from Japan have reported improved safety and efficacy of BPA in select CTEPH patients [46-48]. Despite the recent encouraging results from Japan, BPA should be reserved for these highly specialised and experienced centres. Furthermore, its role in the treatment algorithm for CTEPH remains to be defined when compared with potentially curative surgery and noninvasive medical therapy. Also, despite improvements in the technique and results from these centres, the proper patient selection, treatment objectives and long-term results will need to be defined further.

\section{Future directions}

Despite these exciting advances in CTEPH management, several questions or issues remain, which require further investigation and/or clarification. CTEPH management recommendations have been developed that outline the criteria for CTEPH diagnosis and operability assessment $[5,49,50]$. In order to successfully implement these, a multidisciplinary team of CTEPH physicians, radiologists and expert PEA surgeons, is needed at a designated expert centre. Operability assessment should ideally be performed at these centres together with the responsible PEA surgeon $[5,50]$. CTEPH guidelines have defined an expert centre as one that has sufficient expertise if it performs at least 20 PEA operations per year with a mortality rate of $<10 \%$ [49]. More recent recommendations have suggested that expert centres should strive for improved mortality rates $(<7 \%)$ and early haemodynamic improvements after PEA [5]. However, the operability assessment of CTEPH patients is subjective [51]. More education and international networking are needed to improve infrastructure and increase experience in CTEPH management in emerging centres, particularly those in developing countries.

Recently, PEA has been shown to benefit patients with chronic thromboembolic disease in the absence of $\mathrm{PH}$ [52]. This raises the question of whether a new definition for CTEPH should be implemented that would include such patients [53]. In addition, the expected increase in future medical and interventional treatment options means that terms describing the disease, such as "proximal", "distal" and "microvascular", need to be defined more precisely, so as to enable appropriate treatment choices to be made.

With more questions arising from the growing number of non-pharmacological and pharmacological interventions for CTEPH, a consensus is needed to determine the most relevant treatment outcome parameters for CTEPH patients. While 6-min walk distance is an accepted end-point for early CTEPH studies $[54,55]$, some studies in PAH suggest that it may only have modest validity as a surrogate end-point $[56,57]$. Other end-points, such as long-term survival, disease-free survival, time to clinical worsening and CTEPH-specific quality of life measures, may be more relevant and as such should be further studied. These clinical study data will be critical in guiding how individual treatment strategies can be optimised for CTEPH patients and how treatment options may best be combined. Lastly, other unanswered questions include the role of novel oral anticoagulants and the use of inferior vena cava filters in CTEPH.

\section{Summary}

In conclusion, the recent advancement with the breakthrough discovery of riociguat and the refinements of BPA, mark a major leap in the evolution of CTEPH treatment for the first time since PEA and lung transplantation were introduced. This exciting new era represents the emergence of a new and expanded treatment paradigm for CTEPH. The series of articles in this issue of the European Respiratory Review endeavours to cover the recent developments in the field, as well as exploring the current advances and opportunities in CTEPH, including the role of new diagnostic tools and the integration of new therapies into treatment strategies.

\section{References}

1 Hoeper MM, Mayer E, Simonneau G, et al. Chronic thromboembolic pulmonary hypertension. Circulation 2006; 113: 2011-2020.

2 McLaughlin VV, Archer SL, Badesch DB, et al. ACCF/AHA 2009 expert consensus document on pulmonary hypertension: a report of the American College of Cardiology Foundation Task Force on Expert Consensus Documents and the American Heart Association developed in collaboration with the American College of Chest Physicians; American Thoracic Society, Inc.; and the Pulmonary Hypertension Association. J Am Coll Cardiol 2009; 53: 1573-1619.

3 Moser KM, Bloor CM. Pulmonary vascular lesions occurring in patients with chronic major vessel thromboembolic pulmonary hypertension. Chest 1993; 103: 685-692.

4 Pepke-Zaba J, Jansa P, Kim NH, et al. Chronic thromboembolic pulmonary hypertension: role of medical therapy. Eur Respir J 2013; 985-990.

5 Kim NH, Delcroix M, Jenkins DP, et al. Chronic thromboembolic pulmonary hypertension. J Am Coll Cardiol 2013; 62: Suppl., D92-D99. 

312-320. Hurwitt ES, Schein CJ, Rifkin H, et al. A surgical approach to the problem of chronic pulmonary artery obstruction due to thrombosis or stenosis. Ann Surg 1958; 147: 157-165.

8 Chitwood WR Jr, Sabiston DC Jr, Wechsler AS. Surgical treatment of chronic unresolved pulmonary embolism. Clin Chest Med 1984; 5: 507-536.

9 Carroll D. Chronic obstruction of major pulmonary arteries. Am J Med 1950; 9: 175-185.

10 Houk VN, Hufnagel CA, McClenathan JE, et al. Chronic thrombotic obstruction of major pulmonary arteries: report of a case successfully treated by thrombendarterectomy, and a review of the literature. Am J Med 1963; 35: 269-282.

11 Moser KM, Houk VN, Jones RC, et al. Chronic, massive thrombotic obstruction of the pulmonary arteries. Analysis of four operated cases. Circulation 1965; 32: 377-385.

12 Chitwood WR Jr, Lyerly HK, Sabiston DC Jr. Surgical management of chronic pulmonary embolism. Ann Surg 1985; 201: 11-26.

13 Jault F, Cabrol C. Surgical treatment for chronic pulmonary thromboembolism. Herz 1989; 14: 192-196.

14 Moser KM, Auger WR, Fedullo PF, et al. Chronic thromboembolic pulmonary hypertension: clinical picture and surgical treatment. Eur Respir J 1992; 5: 334-342.

15 Dalen JE, Alpert JS. Natural history of pulmonary embolism. Prog Cardiovasc Dis 1975; 17: 259-270

16 Benotti JR, Ockene IS, Alpert JS, et al. The clinical profile of unresolved pulmonary embolism. Chest 1983; 84: 669-678.

17 Follath F, Burkart F, Schweizer W. Drug-induced pulmonary hypertension? Br Med J 1971; 1: 265-266.

18 Hatano S, Strasser T. Primary Pulmonary Hypertension: Report on a WHO Meeting, Geneva, 15-17 October 1973. Geneva, World Health Organization, 1975.

19 D'Alonzo GE, Barst RJ, Ayres SM, et al. Survival in patients with primary pulmonary hypertension. Results from a national prospective registry. Ann Intern Med 1991; 115: 343-349.

20 Keogh AM, Mayer E, Benza RL, et al. Interventional and surgical modalities of treatment in pulmonary hypertension. J Am Coll Cardiol 2009; 54: Suppl. S, S67-S77.

21 Mayer E, Jenkins D, Lindner J, et al. Surgical management and outcome of patients with chronic thromboembolic pulmonary hypertension: results from an international prospective registry. J Thorac Cardiovasc Surg 2011; 141: $702-710$.

22 Pepke-Zaba J, Delcroix M, Lang I, et al. Chronic Thromboembolic Pulmonary Hypertension (CTEPH): results from an International Prospective Registry. Circulation 2011; 124: 1973-1981.

23 Galiè N, Kim NH. Pulmonary microvascular disease in chronic thromboembolic pulmonary hypertension. Proc Am Thorac Soc 2006; 3: 571-576.

24 Bonderman D, Skoro-Sajer N, Jakowitsch J, et al. Predictors of outcome in chronic thromboembolic pulmonary hypertension. Circulation 2007; 115: 2153-2158.

25 Dartevelle P, Fadel E, Mussot S, et al. Chronic thromboembolic pulmonary hypertension. Eur Respir J 2004; 23 : 637-648.

26 Kim NH. Riociguat: an upcoming therapy in chronic thromboembolic pulmonary hypertension? Eur Respir Rev 2010; 19: 68-71.

27 Humbert M. Pulmonary arterial hypertension and chronic thromboembolic pulmonary hypertension: pathophysiology. Eur Respir Rev 2010; 19: 59-63.

28 Rich S. Executive Summary from the World Symposium on Primary Pulmonary Hypertension. September 6-10, 1998, Evian, France; cosponsored by the World Health Organization. Geneva, World Health Organization, 1998.

29 Simonneau G, Galiè N, Rubin LJ, et al. Clinical classification of pulmonary hypertension. J Am Coll Cardiol 2004; 43: Suppl. Sf, 5S-12S.

30 Humbert M, McLaughlin VV. Introduction: The 4th World Symposium on Pulmonary Hypertension. J Am Coll Cardiol 2009; 54: Suppl. S, S1-S2.

31 Giaid A, Yanagisawa M, Langleben D, et al. Expression of endothelin-1 in the lungs of patients with pulmonary hypertension. N Engl J Med 1993; 328: 1732-1739.

32 Tuder RM, Cool CD, Geraci MW, et al. Prostacyclin synthase expression is decreased in lungs from patients with severe pulmonary hypertension. Am J Respir Crit Care Med 1999; 159: 1925-1932.

33 Bresser P, Pepke-Zaba J, Jais X, et al. Medical therapies for chronic thromboembolic pulmonary hypertension: an evolving treatment paradigm. Proc Am Thorac Soc 2006; 3: 594-600.

34 Delcroix M. Chronic post-embolic pulmonary hypertension: a new target for medical therapies? Eur Respir Rev 2013; 22: 258-264.

35 Stasch JP, Pacher P, Evgenov OV. Soluble guanylate cyclase as an emerging therapeutic target in cardiopulmonary disease. Circulation 2011; 123: 2263-2273.

36 Ghofrani HA, D'Armini AM, Grimminger F, et al. Riociguat for the treatment of chronic thromboembolic pulmonary hypertension. N Engl J Med 2013; 369: 319-329.

37 Simonneau G, D'Armini A, Ghofrani HA, et al. Riociguat for the treatment of chronic thromboembolic pulmonary hypertension (CTEPH): 1-year results from the CHEST-2 Long-Term Extension study. Chest 2013; 144: 1023A.

38 Bresser P, Fedullo PF, Auger WR, et al. Continuous intravenous epoprostenol for chronic thromboembolic pulmonary hypertension. Eur Respir J 2004; 23: 595-600.

39 Jensen KW, Kerr KM, Fedullo PF, et al. Pulmonary hypertensive medical therapy in chronic thromboembolic pulmonary hypertension before pulmonary thromboendarterectomy. Circulation 2009; 120: 1248-1254.

40 Kramm T, Eberle B, Krummenauer F, et al. Inhaled iloprost in patients with chronic thromboembolic pulmonary hypertension: effects before and after pulmonary thromboendarterectomy. Ann Thorac Surg 2003; 76: 711-718.

41 Nagaya N, Sasaki N, Ando M, et al. Prostacyclin therapy before pulmonary thromboendarterectomy in patients with chronic thromboembolic pulmonary hypertension. Chest 2003; 123: 338-343.

42 Reesink HJ, Surie S, Kloek JJ, et al. Bosentan as a bridge to pulmonary endarterectomy for chronic thromboembolic pulmonary hypertension. J Thorac Cardiovasc Surg 2010; 139: 85-91.

43 Voorburg JA, Cats VM, Buis B, et al. Balloon angioplasty in the treatment of pulmonary hypertension caused by pulmonary embolism. Chest 1988; 94: 1249-1253. 
44 Andreassen AK, Ragnarsson A, Gude E, et al. Balloon pulmonary angioplasty in patients with inoperable chronic thromboembolic pulmonary hypertension. Heart 2013; 99: 1415-1420.

45 Feinstein JA, Goldhaber SZ, Lock JE, et al. Balloon pulmonary angioplasty for treatment of chronic thromboembolic pulmonary hypertension. Circulation 2001; 103: 10-13.

46 Kataoka M, Inami T, Hayashida K, et al. Percutaneous transluminal pulmonary angioplasty for the treatment of chronic thromboembolic pulmonary hypertension. Circ Cardiovasc Interv 2012; 5: 756-762.

47 Mizoguchi H, Ogawa A, Munemasa M, et al. Refined balloon pulmonary angioplasty for inoperable patients with chronic thromboembolic pulmonary hypertension. Circ Cardiovasc Interv 2012; 5: 748-755.

48 Sugimura K, Fukumoto Y, Satoh K, et al. Percutaneous transluminal pulmonary angioplasty markedly improves pulmonary hemodynamics and long-term prognosis in patients with chronic thromboembolic pulmonary hypertension. Circ J 2012; 76: 485-488.

49 Galiè N, Hoeper MM, Humbert M, et al. Guidelines for the diagnosis and treatment of pulmonary hypertension: The Task Force for the Diagnosis and Treatment of Pulmonary Hypertension of the European Society of Cardiology (ESC) and the European Respiratory Society (ERS), endorsed by the International Society of Heart and Lung Transplantation (ISHLT). Eur Heart J 2009; 30: 2493-2537.

50 Wilkens $\mathrm{H}$, Lang I, Behr J, et al. Chronic thromboembolic pulmonary hypertension (CTEPH): updated recommendations of the Cologne Consensus Conference 2011. Int J Cardiol 2011; 154: Suppl. 1, S54-S60.

51 Konstantinides SV, Torbicki A, Agnelli G, et al. 2014 ESC Guidelines on the diagnosis and management of acute pulmonary embolism. Eur Heart J 2014: 35: 3033-3080.

52 Taboada D, Pepke-Zaba J, Jenkins DP, et al. Outcome of pulmonary endarterectomy in symptomatic chronic thromboembolic disease. Eur Respir J 2014; 1635-1645.

53 de Parrot M, Mayer E. Chronic thromboembolic pulmonary hypertension: do we need a new definition? Eur Respir J 2014; 44: 1401-1403.

54 Suntharalingam J, Goldsmith K, Toshner M, et al. Role of NT-proBNP and 6MWD in chronic thromboembolic pulmonary hypertension. Respir Med 2007; 101: 2254-2262.

55 Suntharalingam J, Treacy CM, Doughty NJ, et al. Long-term use of sildenafil in inoperable chronic thromboembolic pulmonary hypertension. Chest 2008; 134: 229-236.

56 Gabler NB, French B, Strom BL, et al. Validation of 6-minute walk distance as a surrogate end point in pulmonary arterial hypertension trials. Circulation 2012; 126: 349-356.

57 Gaine S, Simonneau G. The need to move from 6-minute walk distance to outcome trials in pulmonary arterial hypertension. Eur Respir Rev 2013; 22: 487-494. 